\title{
MJN \\ AWARENESS AND KNOWLEDGE TOWARD BREAST CANCER AND BREAST SELF-EXAMINATION: A CROSS-SECTIONAL DESCRIPTIVE STUDY AMONG UNDERGRADUATE FEMALE STUDENTS AT CAIRO UNIVERSITY, EGYPT
}

\author{
Seham Kamal Mohamed \\ Medical Surgical Nursing, Faculty of Nursing, Cairo University, Egypt \\ *Corresponding Author's Email:seham.kamal@cu.edu.eg; seham_kamal2008@yahoo.com
}

\begin{abstract}
Introduction: Breast cancer (BC) accounts for $38.85 \%$ of total female cancer cases in Egypt and is the most prevalent cancer among Egyptian women. Early detection of breast cancer increases the effectiveness of the treatment, which results in a better prognosis, reducing the morbidity and mortality rates. Breast selfexamination (BSE) is an important screening practice, a simple, economical, and noninvasive screening method for early detection of breast cancer. Methods: A cross-sectional descriptive design was utilized to conduct the study. The study was conducted at Cairo University, Egypt. A convenient sample consisted of 500 female students were interviewed. The tool used for data collection was constructed by the researcher which divided into four parts: The first part was concerned with demographic general questions. The second part was related to the knowledge of breast cancer. The third part is concerned with knowledge about the risk factors of breast cancer. The fourth part dealt with knowledge about breast self- examination. Results: The study findings showed that the overall level of knowledge about breast cancer and breast self-examination were moderate ( $47 \%$ and $47.8 \%$ respectively). There was no association between total knowledge about breast cancer and total knowledge about breast self- examination $(P=0.388)$. There is statistically significant association between place of residence and total knowledge about breast self-examination $(P=0.001)$, there is statistically significant association between total knowledge of breast cancer with having family history of breast cancer $(p=0.022)$. There is statistically significant association $(P=0.03)$ between place of residence and total knowledge about breast cancer and showed that there is highly statistically significant association (0.0001) between marital status and total knowledge about breast cancer. Conclusion: Our study findings have shown that the level of awareness and knowledge about breast cancer and breast self-examination was generally moderate. Therefore, it is essential to increase the conduct for public interventions that increase awareness and encourage women to practice BSE on a regular basis as a national trend.
\end{abstract}

\section{Breast Cancer; Breast Self-Examination; Awareness; Knowledge}

\section{INTRODUCTION}

Breast cancer $(\mathrm{BC})$ is the top cancer in women, both in the developed and in the developing world. Also, the second most common cancer overall worldwide (Bray et al., 2018; Erdem \& Toktas, 2016; Oeffinger et al., 2015). While breast cancer is a global issue, the figure for people suffering from breast cancer is alarming. Breast cancer accounts for $38.85 \%$ of total female cancer cases in Egypt and is the most prevalent cancer among Egyptian women. In Egypt, the median age diagnosed for breast is ten years younger than united states and Europe and causes the greatest number of cancer- related deaths among women (Mostafa, 2016). In 2018, it is estimated that 6,27,000 women died from breast cancer- that is approximately $15 \%$ of all cancer deaths among women (American Cancer Society, 2017).

Early detection of breast cancer increases the 
effectiveness of the treatment, which results in a better prognosis, reducing the morbidity and mortality rates (Ahmed et al., 2018; Ngugi et al., 2017). The risk factors for breast cancer include increased age, women with history or family history of breast cancer, women who started menstruation early or went through menopause late, and the use of hormonal replacement therapy (HRT) with combined estrogen and progesterone. Breast cancer in the early stages typically do not produce symptoms but as the tumor enlarges, symptoms produced include; painless lump in the breast, lump under the armpit, breast pain, swelling or thickness of the breast skin, spontaneous discharge of the nipple maybe bloody and erosion or inversion in the nipple. The control of breast cancer in most developing countries including Egypt is under the sponsorships of national control programs promoted by the $\mathrm{WHO}$, and this involves educating and screening young women for signs of breast cancer. The earlier breast cancer is detected, the better the effectiveness of the treatment and the likelihood of survival (Azemfac et al., 2019; Sama et al., 2017).

WHO promotes $\mathrm{BC}$ control within the context of comprehensive national cancer control programs that are integrated into noncommunicable diseases and other related problems. Comprehensive cancer control involves prevention, early detection, diagnosis and treatment, rehabilitation, and palliative care. Early detection plays a crucial role for BC. It appears that the best way to save women's lives is to increase their awareness of the potential harms of $\mathrm{BC}$, to raise their level of awareness about early warning signs, risk factors, and early detection procedures for this disease (Birhane et al., 2017; Erdem \& Toktas, 2016). Breast self-examination (BSE) is an important screening practice, a simple, economical, and noninvasive screening method for early detection of BC (Mekonnen \& Asefa, 2019; Ahmed et al., 2018).

Breast cancer screening methods include breast selfexamination (BSE), clinical breast examination and mammography, and these are usually done in combination. BSE is the recommended method in developing countries because it is easy, convenient, private, safe and requires no specific equipment (Mekonnen \& Asefa, 2019; Ahmed et al., 2018). Its purpose is to make women familiar with both the appearance and feel of their breasts as early as possible, so that they will be able to easily detect changes in their breast (Sama et al., 2017; Ibnawadh et al., 2017). Several studies have revealed that a positive association exists between the performance of BSE and detection of breast cancer, and most of the early breast tumor detection have been selfdiscovered (Taleghani, Kianpour \& Tabatabaiyan, 2019; Nde et al., 2015).

Breast Self-Examination (BSE) was first tested in Finland around 1970s developed by Gisela Gastrin and later a women organization promoted BSE training in 1992 (Ali et al., 2019; Gupta et al., 2019). BSE is the inspection of a woman's own breasts on a regular, repetitive basis for the purpose of detecting any abnormal lumps or swelling in breast, preferably between the $7^{\text {th }}$ and $10^{\text {th }}$ day of each menstrual cycle (Dadzi \& Adam, 2019). Women age 20-39 should have a physical exam of their breast or clinical breast exam at least every three years, performed by a health care professional. The American Cancer Society currently recommends women to perform BSE starting from early $20 \mathrm{~s}$ and prompt, immediate reporting of any abnormal breast symptoms to health care professionals (Ali et al., 2019; Gwarzo, Sabitu \& Idris, 2016).

Raising the awareness of BSE help in early detection of breast cancer and help in decreasing morbidity and mortality rates. Early detection is based on the concept that the sooner the cancer is detected, the more effective the treatment is likely to be. It was consequently important to ascertain the level of awareness and knowledge towards BC and BSE among female. Hence this study was undertaken with the following study objectives

1. To assess awareness and knowledge towards BC and BSE among female students at Cairo University.

2. To understand the association between awareness, knowledge towards BSE among sociodemographic variables.

3. To identify the factors affecting awareness and knowledge scores regarding breast cancer and BSE in female students.

\section{Research Questions}

1. What is the level of awareness and knowledge about breast cancer among female students at Cairo University?

2. What is the level of awareness and knowledge about breast self-examination among female students at Cairo University?

3. Is there a relationship between breast cancer knowledge score and total knowledge score about breast self-examination? 
4. Is there a relationship between breast cancer knowledge score and sociodemographic characteristics?

5. Is there a relationship between breast selfexamination knowledge score and sociodemographic characteristics?

\section{METHODOLOGY}

\section{Research Design}

A cross-sectional descriptive design was utilized to conduct the study. This type of design provides the researcher with numerous information at once such as patients sociodemographic characteristics in relation to knowledge of breast cancer and breast self-examination (Reymen et al., 2016; Wood \& Haber, 2015).

\section{Setting}

The study was conducted at Cairo University, Egypt from June 2018 to November 2018.

\section{Sample}

A convenient sample consisted of 500 female students. The study sample was calculated using of Power analysis of 95 ( $\beta=1-0.95=0.5)$ at $\alpha 0.05$ (onesided) with large effect size $(0.5)$ was used as the significance level.

\section{Tools}

\section{Data was collected using the following tools}

For data collection the tool constructed by the researcher after reviewing the related literature which divided into four parts

The first part: Is concerned with demographic general questions that include

Age, marital status, level of educational year and others.

The second part: Is related to the knowledge of females of breast cancer. This level of knowledge is divided to scores out of (12). The score is aggregated to three levels as poor (below 40\%), moderate level (40\% to $70 \%$ ), and good level (above $70 \%$ )

The third part: Is concerned with knowledge of females about the risk factors of breast cancer. This level of knowledge is divided to scores out of (6). The score is aggregated to three levels as poor (below 40\%), moderate level $(40 \%$ to $70 \%$ ), and good level (above $\mathbf{7 0 \% )}$

The fourth part: Is concerned with knowledge of females about breast self- examination. This level of knowledge is divided to scores out of (10). The score is aggregated to three levels as poor (below 40\%), moderate level (40\% to $70 \%$ ), and good level (above $70 \%)$

\section{Procedure}

Each female was informed about the purpose of the study. The researcher emphasized that the participation in the study is voluntary. Anonymity and confidentiality were assured through gathering the data. Then an informed oral consent was taken from the female who met the selection criteria and accepted to participate in the study.

\section{Initial Phase}

It this phase the researcher was searching the literature review using scientific data base. The researcher was writing study methodology to conduct the study.

\section{Planning Phase}

Based on the previous phase the pilot study was conducted to ensure clarity and validity of the study tool.

\section{Implementation Phase}

At the beginning of this phase, the researcher ensured to explain nature and purpose of the study to the students. The students of the study were interviewed for 20 minutes to fill in the structured questionnaire related to demographic data as well as knowledge of breast cancer consisting of 12 questions answered with (yes or no); the answer scored as (yes $=1, \mathrm{no}=0$ ) and breast selfexamination consist of 10 questions answered with (yes or no) the answer scored as (yes $=1$, no $=0$ ). Respondent considered to have poor level of knowledge when score is less than $40 \%$ of total knowledge score, have moderate level of knowledge when total score of knowledge was $40 \%$ to $70 \%$ and good level of knowledge when have above $70 \%$ of total knowledge score. Once the interview was ended the researcher provided the students with instructions regarding breast self-examination technique and benefits.

\section{DataAnalysis}

Statistical package for the social science (SPSS) program, version 20 was used for data analysis. The socio-demographic variables such as age, education level, occupation and family income were analyzed using descriptive statistics (frequency and percentage). Association between patients' knowledge, awareness of breast cancer, breast self-examination and selected socio- 
demographic variables was assessed by independent $t$ test. Level of significance was adopted at $P<0.05$.

\section{RESULTS}

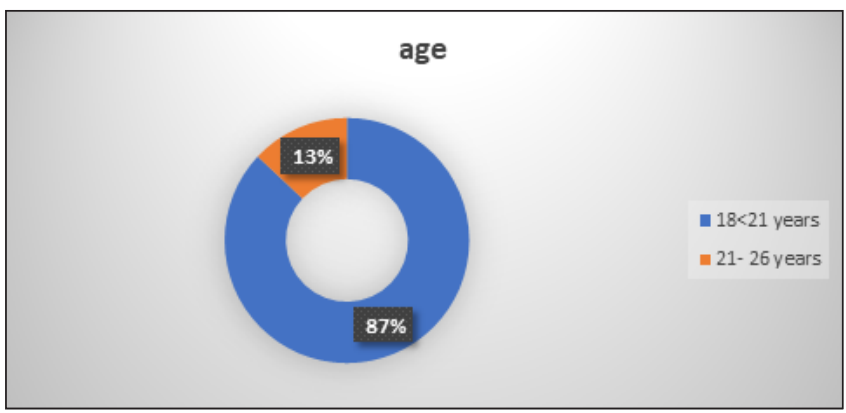

Figure 1: Frequency Distribution of Age (no.=500)

Figure 1 clarified that the majority $(87 \%)$ of study participants age from 18 to 21 years.

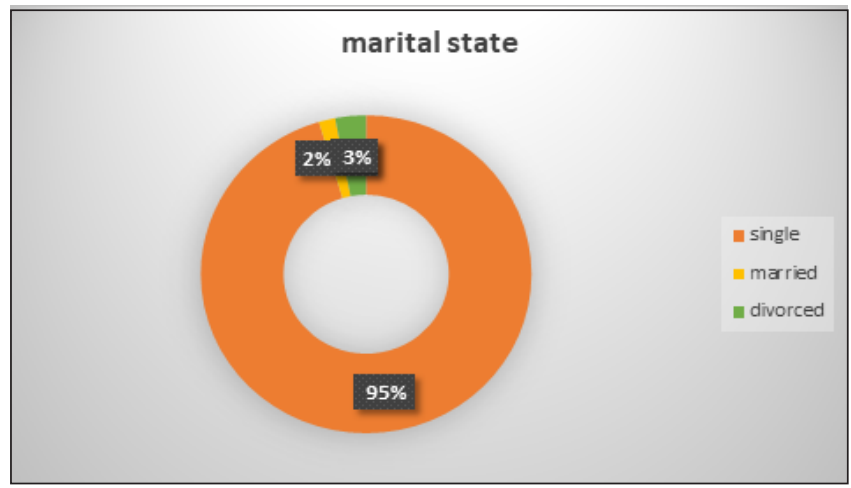

Figure 2: Frequency Distribution of Marital Status (no. $=500)$

Figure 2 clarified that most of the study participants (95\%) were single.

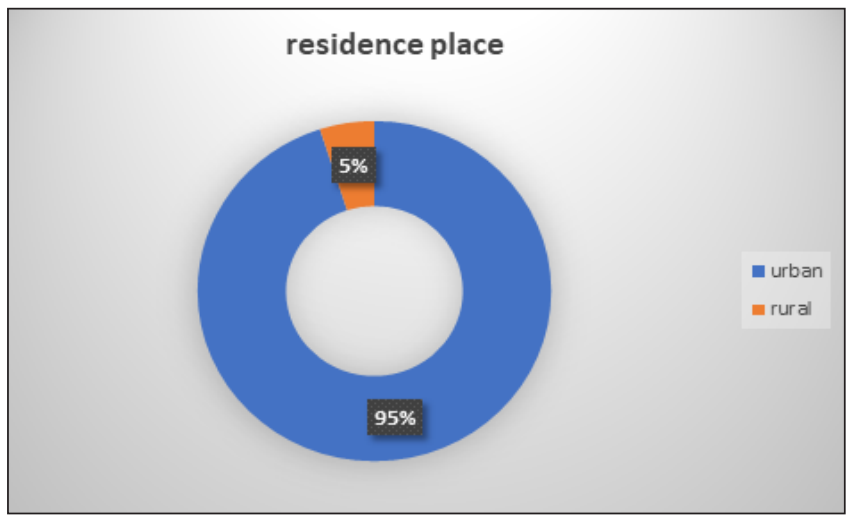

Figure 3: Frequency Distribution of Place of Residence $($ no $=500)$

In relation to place of residence figure 3 clarified that most current study respondents were from urban regions.
Family members diagnosed with breast cancer

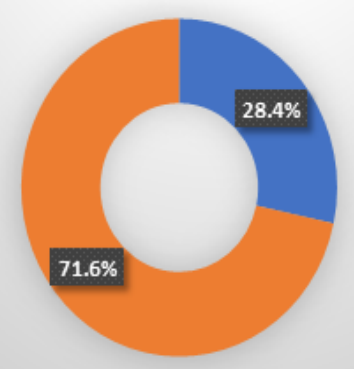

myes

mo

Figure 4: Frequency Distribution of Family Member Diagnosed with Breast Cancer $(n o=500)$

In relation to family history of breast cancer figure 4 showed that approximately three quarters $(71.6 \%)$ of study sample have no family history of breast cancer.

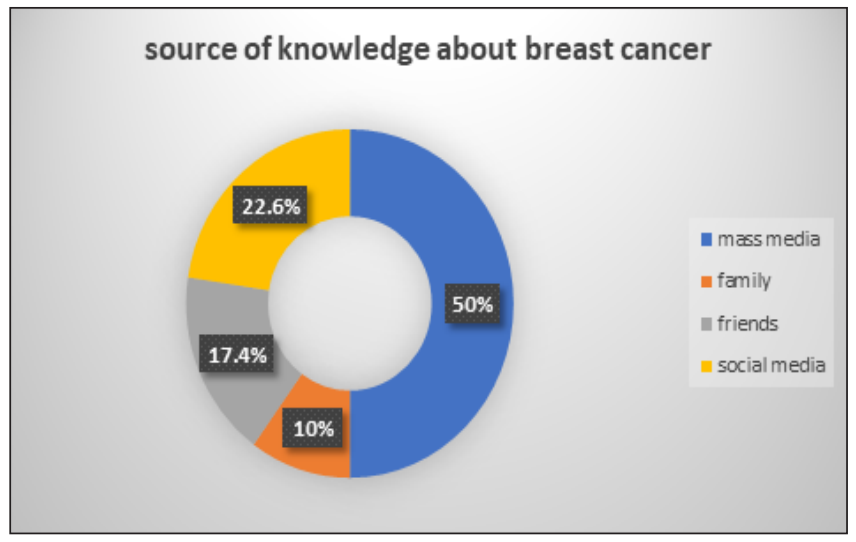

Figure 5: Frequency Distribution of Source of Knowledge about Breast Cancer (no=500)

Regarding the source of knowledge about breast cancer figure 5 clarified that half of the study sample $(50 \%)$ had their information from mass media and about one quarter $(22.6 \%)$ gathered information about breast cancer from social media.

Table 1 shows that the majority of participants (93.6\%) have heard about breast cancer and $60.2 \%$ of participants think that exposure to radiation increase probability of having breast cancer, while $91.6 \%$ didn't think the beginning of menstruation at age less than 12 years old increase the probability of having breast cancer. About $83.8 \%$ didn't think the infertility increase the probability of having breast cancer, and $78.6 \%$ didn't think obesity increase the probability of having breast cancer. 
Table 1: Knowledge about Breast Cancer $(\mathrm{No}=500)$

\begin{tabular}{|c|c|c|c|c|c|}
\hline \multirow[t]{2}{*}{ No. } & \multirow[t]{2}{*}{ Variable } & \multicolumn{2}{|c|}{ Yes } & \multicolumn{2}{|c|}{ No } \\
\hline & & No. & $\%$ & No. & $\%$ \\
\hline 1. & Did you hear about breast cancer? & 468 & 93.60 & 32 & 6.40 \\
\hline 2. & $\begin{array}{l}\text { Is age a risk factor for the } \\
\text { beginning if the menstruation is } \\
\text { less than } 12 \text { years old? }\end{array}$ & 133 & 26.60 & 367 & 73.40 \\
\hline 3. & $\begin{array}{l}\text { Is breast cancer only found } \\
\text { among women? }\end{array}$ & 174 & 34.80 & 326 & 65.20 \\
\hline 4. & $\begin{array}{l}\text { Do you think the infertility } \\
\text { increase the probability of having } \\
\text { breast cancer? }\end{array}$ & 81 & 16.20 & 419 & 83.80 \\
\hline 5. & $\begin{array}{l}\text { Do you think increase in age } \\
\text { increases probability of having } \\
\text { breast cancer? }\end{array}$ & 205 & 41 & 295 & 59 \\
\hline 6. & $\begin{array}{l}\text { Do you think menopause after } 50 \\
\text { years of age increase the } \\
\text { probability of having breast } \\
\text { cancer? }\end{array}$ & 139 & 27.80 & 361 & 72.20 \\
\hline 7. & $\begin{array}{l}\text { Do you think if a member of the } \\
\text { family was diagnosed with breast } \\
\text { cancer increases the probability } \\
\text { of having breast cancer in the } \\
\text { family? }\end{array}$ & 198 & 39.60 & 302 & 60.40 \\
\hline 8. & $\begin{array}{l}\text { Do you think smoking increase } \\
\text { the probability of having breast } \\
\text { cancer? }\end{array}$ & 279 & 55.80 & 221 & 44.20 \\
\hline 9. & $\begin{array}{l}\text { Do you think diet rich with fat } \\
\text { increase the probability of having } \\
\text { breast cancer? }\end{array}$ & 207 & 41.40 & 293 & 58.60 \\
\hline 10. & $\begin{array}{l}\text { Do you think exposure to } \\
\text { radiation increase probability of } \\
\text { having breast cancer? }\end{array}$ & 301 & 60.20 & 199 & 39.80 \\
\hline 11. & $\begin{array}{l}\text { Do you think the beginning of } \\
\text { menstruation at age less than } 12 \\
\text { years old increase the probability } \\
\text { of having breast cancer? }\end{array}$ & 42 & 8.40 & 458 & 91.60 \\
\hline 12. & $\begin{array}{l}\text { Do you think obesity increase the } \\
\text { probability of having breast } \\
\text { cancer? }\end{array}$ & 107 & 21.40 & 393 & 78.60 \\
\hline
\end{tabular}

Table 2: Knowledge about Early Signs and Symptoms of Breast Cancer $(\mathrm{No}=500)$

\begin{tabular}{|l|c|c|c|c|}
\hline \multirow{2}{*}{ Variable } & \multicolumn{2}{|c|}{ Correct } & \multicolumn{2}{c|}{ Incorrect } \\
\cline { 2 - 5 } & No. & $\mathbf{\%}$ & No. & $\%$ \\
\hline $\begin{array}{l}\text { A-presence of bloody or clear secretions from } \\
\text { the nipple. }\end{array}$ & 272 & 54.40 & 228 & 45.60 \\
\hline B-Presence of enlargement in one of the breasts. & 350 & 70 & 150 & 30 \\
\hline C- Change in normal color of the skin. & 313 & 62.60 & 187 & 37.40 \\
\hline D-Presence of painless lump in the breast. & 392 & 78.40 & 108 & 21.60 \\
\hline E- Enlargement of axillary lymph nodes. & 342 & 68.40 & 158 & 31.60 \\
\hline F- Presence of descending nipple. & 223 & 44.60 & 277 & 55.40 \\
\hline
\end{tabular}

Table 2 shows that $78.4 \%$ of study participants know that presence of painless lump in the breast is early signs of breast cancer, $70 \%$ know that presence of enlargement in one of the breast is early signs of breast cancer, $68.4 \%$ know that enlargement of axillary lymph nodes is early signs of breast cancer and $55.4 \%$ didn't know that presence of descending nipple is early signs of breast cancer.
Table 3: Knowledge about breast Self-Examination $(\mathrm{No}=500)$

\begin{tabular}{|c|l|c|c|c|c|}
\hline No. & Variable & \multicolumn{2}{|c|}{ Yes } & \multicolumn{2}{|c|}{ No } \\
\cline { 2 - 6 } & & No. & \% & No. & $\%$ \\
\hline 1. & $\begin{array}{l}\text { Did you hear about breast self- } \\
\text { examination? }\end{array}$ & 399 & 79.80 & 101 & 20.20 \\
\hline 2. & $\begin{array}{l}\text { Do you know that breast self- } \\
\text { examination is useful tool for early } \\
\text { detection about breast cancer? }\end{array}$ & 399 & 79.80 & 101 & 20.20 \\
\hline 3. & $\begin{array}{l}\text { Women should start practicing in the } \\
\text { breast self- examination at early 20s? }\end{array}$ & 204 & 40.80 & 296 & 59.20 \\
\hline 4. & $\begin{array}{l}\text { The best time for performing breast } \\
\text { self-examination is at } 7^{\text {th }} \text { and 10 } \\
\text { from period? }\end{array}$ & 50 & 10 & 450 & 90 \\
\hline 5. & $\begin{array}{l}\text { Breast self- examination should be } \\
\text { done once monthly? }\end{array}$ & 258 & 51.60 & 242 & 48.40 \\
\hline 6. & $\begin{array}{l}\text { Is there special technique for breast self } \\
- \text { examination? }\end{array}$ & 117 & 23.40 & 383 & 76.60 \\
\hline 7. & $\begin{array}{l}\text { Are there other methods for breast } \\
\text { examination? }\end{array}$ & 109 & 21.80 & 391 & 78.20 \\
\hline 8. & $\begin{array}{l}\text { The breast self- examination is } \\
\text { performed by women themselves? }\end{array}$ & 218 & 43.60 & 282 & 56.40 \\
\hline
\end{tabular}

Table 3 showed that, $79.8 \%$ of study participants heard about breast self- examination and $79.8 \%$ of them knew that the breast self-examination is a useful tool for early detection about breast cancer and $40.8 \%$ of them knew that the age of starting breast self- examination. Majority of the study participants $(90 \%)$ didn't know the best time for performing breast self-examination. approximately half of participants know that breast selfexamination done once monthly, and $23.4 \%$ of them know that breast self-examination needs special technique to perform it. Above three quarters (78.2\%) of participants told that there are no other methods for breast examination, while near half $(43.6 \%)$ of participants know that breast self-examination is performed by women themselves.

Table 4: Mean and Standard Deviation of Participants Knowledge about Breast Cancer and Breast SelfExamination (No=500)

\begin{tabular}{|l|c|c|c|c|}
\hline & Minimum & Maximum & Mean & Std. Deviation \\
\hline $\begin{array}{l}\text { Total Knowledge } \\
\text { about breast cancer }\end{array}$ & 1.00 & 16.00 & 7.59 & 3.34172 \\
\hline $\begin{array}{l}\text { Total knowledge about } \\
\text { breast self - } \\
\text { examination }\end{array}$ & 2.00 & 9.00 & 4.32 & 1.49736 \\
\hline
\end{tabular}

Table 4 shows that participants have moderate (47\%) about breast cancer and moderate knowledge (mean= $47.8 \%$ ) about breast self- examination.

Table 5 shows that there is no significant association between total knowledge about breast cancer and total knowledge about breast self- examination. 
Table 5: Relationship Between Total Knowledge about Breast Cancer and Total Knowledge about Breast SelfExamination $(\mathrm{No}=500)$

\begin{tabular}{|l|c|c|c|c|}
\hline & Mean & Std. Deviation & $\boldsymbol{r}$ & $\boldsymbol{p}$ \\
\hline $\begin{array}{l}\text { Total Knowledge about } \\
\text { breast cancer }\end{array}$ & 7.5960 & 3.34172 & \multirow{2}{*}{0.039} & 0.388 \\
\cline { 1 - 3 } $\begin{array}{l}\text { Total knowledge about } \\
\text { breast self-examination }\end{array}$ & 4.3200 & 1.49736 & \\
\hline
\end{tabular}

Table 6: Mean and Standard Deviation of Participants Knowledge about Breast Self- Examination and Knowledge about Breast Cancer $(\mathrm{No}=500)$

\begin{tabular}{|l|l|l|l|c|}
\hline $\begin{array}{l}\text { There is someone from your family } \\
\text { diagnosed with breast cancer? }\end{array}$ & Mean & Std. Deviation & $\boldsymbol{r}$ & $\boldsymbol{p}$ \\
\hline Total Knowledge about breast cancer & 7.5960 & 3.34172 & 0.103 & 0.022 \\
\hline $\begin{array}{l}\text { Total knowledge about breast self- } \\
\text { examination }\end{array}$ & 4.3200 & 1.49736 & 0.058 & 0.198 \\
\hline
\end{tabular}

Table 6 shows that there is statistically significant association between total knowledge of breast cancer with having family history of breast cancer $(p=0.022)$.

Table 7: Relationship Between Total Knowledge about Breast Cancer with Sociodemographic Variables $(\mathrm{No}=500)$

\begin{tabular}{|l|c|c|c|c|c|}
\hline Variable & Categories & mean & SD & Test & $\boldsymbol{P}$ \\
\hline $\begin{array}{l}\text { Residence } \\
\text { place }\end{array}$ & Urban & 7.6092 & 3.39328 & $T=0.394$ & 0.03 \\
\cline { 2 - 4 } Marital state & Rural & 7.3333 & 2.09900 & & \\
\cline { 2 - 4 } & Single & 7.4295 & 3.17506 & \multirow{2}{*}{$F=29.23$} & 0.0001 \\
\cline { 2 - 4 } & Married & 16.0000 & 0.00000 & & \\
\cline { 2 - 4 } & Widowed & 8.2941 & 3.60147 & & \\
\hline
\end{tabular}

Table 7 showed that there is statistically significant association $(P=0.03)$ between place of residence and total knowledge about breast cancer and showed that there is highly statistically significant association $(0.0001)$ between marital status and total knowledge about breast cancer.

Table 8: Relationship Between Total Knowledge about Breast Self-Examination with Sociodemographic Variables $(\mathrm{No}=500)$

\begin{tabular}{|l|c|c|c|c|c|}
\hline Variable & Categories & mean & SD & Test & $\boldsymbol{P}$ \\
\hline \multirow{2}{*}{ Residence place } & urban & 4.3025 & 1.46139 & \multirow{2}{*}{$T=1.16$} & \multirow{2}{*}{0.001} \\
\cline { 2 - 5 } & rural & 4.6667 & 2.09900 & & \\
\hline \multirow{3}{*}{ Marital state } & single & 4.3179 & 1.52130 & \multirow{2}{*}{$F=1.084$} & 0.339 \\
\cline { 2 - 4 } & married & 5.0000 & 0.00000 & & \\
\cline { 2 - 4 } & widowed & 4.0588 & 1.02899 & & \\
\hline
\end{tabular}

Table 8 showed that there is statistically significant association between place of residence and total knowledge about breast self- examination $(P=0.001)$

\section{DISCUSSION}

Since breast cancer is difficult to prevent, it becomes increasingly important to find ways to detect it at an early stage, so it has been shown to improve patient mortality. One of the easiest and safest methods to recognize any breast abnormality is Breast self-examination (BSE), getting it essential for all females to be aware of it and to practice it regularly. BSE is possibility for women to start in their 20s. Women should be informed about the benefits and restrictions of BSE. Our study outcomes have shown that the level of awareness and knowledge about breast cancer and breast self-examination was generally moderate. About $(90 \%)$ and $(80 \%)$ had previously heard about breast cancer (BC) and heard about breast selfexamination respectively. Similar findings were found in study carried out in Malaysia by Ali, et al., 2019 reported that about $99 \%$ of respondents have known previously about breast cancer whereas the awareness regarding BC was moderate. A study done in Cameroon revealed that $44 \%$ of their respondents were had lack of knowledge regarding breast self-examination which corresponding to our study findings (Nde et al., 2015), also study conducted in Ghana on reproductive age women revealed the same results (Dadzi \& Adam, 2019).

Similarly, the current findings were in correspondence with study conducted in Ethiopia reported that the overall knowledge of female undergraduate students regarding BSE is found to be 167 (55.7\%) (Mekonnen \& Asefa, 2019). Also study in Nigeria have shown only about $50 \%$ reported adequate Knowledge of BSE (Adetule, 2016). The current study revealed that there was no significant association between total knowledge about breast cancer and total knowledge about breast self-examination. The moderate level of knowledge in the current study could be related to the lack of health education about breast selfexamination despite the national trend and awareness campaign toward breast cancer nowadays. Although the participants of the current study were in higher education their level of knowledge and awareness regard very important and dangerous health problem was moderate, so educational interventions are required in Egypt to encourage young women to acquire knowledge and raising their awareness toward performing BSE regularly so that breast abnormalities can be detected early on and dangerous consequences can be minimized.

Also (79.8\%) of the current study participants know that the breast self- examination is a useful tool for early detection about breast cancer, this come in agreements with findings of survey study carried out on student 
females in Pakistan reported that majority of the participants considered that BSE is important in the early detection of breast cancer (Ahmed et al., 2018). Regarding the best time for performing BSE The findings of the current study show that only $10 \%$ of study participants were know that the best time for performing BSE is on $7^{\text {th }}$ and $10^{\text {th }}$ day of period these results are in line but few than results of study done in Pakistan on female students showed that one third of respondents knew that the best time for performing BSE is week after menstruation (Ahmed et al., 2018). The current study revealed that moderate level of knowledge about early signs and symptoms of breast cancer, these results were in line with study done in Ghana on reproductive age women showed that only $64.9 \%$ of the respondents demonstrated adequate knowledge of symptoms and preventive measures for breast cancer (Dadzi \& Adam, 2019).

In relation to source of information about breast cancer $(50 \%)$ of the study respondent their most commonly source of information about breast cancer was mass media this came in agreement with Ahmed et al., (2018) and Kifle et al., (2016) showed that media is the most commonly encountered source of awareness of BSE. Also, in a study done in Cameroon showed that the main source of information on BSE as cited by their respondents was television (Nde et al., 2015). These findings showed that the media especially television can be used to increase awareness of women on the importance of BSE, as well as instruct women on how to perform BSE. Ahmed et al., (2018) in a study carried out in Pakistan they observed that age and marital status were not associated with a higher level of knowledge this result was contradicted with our study findings which revealed that there is highly statistically significant association $(P=0.0001)$ between marital status and total knowledge about breast cancer. The majority $(95 \%)$ of study participants in the current study, were single this was in line with a study done in Malaysia on female students who mentioned that $90 \%$ of participants were singles. This could explain that significant association, also those females were in higher education and may be exposed to programs that could raise their awareness and increase their knowledge(Ali et al., 2019).

In relation to place of residence the majority $(95 \%)$ of the current study participants were urban residents the study findings revealed that there was statistically significant association between place of residence with total knowledge about breast cancer and total knowledge about breast self-examination $(P=0.03$ and $P=0.001$ respectively). This was in line with Ali et al., (2019) a study done in Malaysia on female students who mentioned that for native location categories, the town dwellers showed better awareness $(P=0.07)$ and knowledge towards BC and BSE than rural areas respondents. Similarly, a study by Dadzi \& Adam, (2019) found that show an overall lack of comprehensive knowledge of breast cancer and BSE among rural women in the Volta region of Ghana.

Study findings also showed that there was statistically significant association between total knowledge of breast cancer and total knowledge of breast self- examination with having family history of breast cancer. Contrasting results were seen in a study conducted in Malaysia on female students who found that among the participants with positive and negative family history of breast cancer, both showed identical poor levels of awareness and knowledge towards $\mathrm{BC}$ and BSE (Ali et al., 2019). In the current study the statistically significant association between total knowledge of breast cancer and total knowledge of breast self-examination with having family history of breast cancer it could be explained as the participants who had family history of breast cancer may be exposed more for issues and related information and treatments linked to breast cancer than those participants who didn't have family history of such disease. The finding of the present study was supported by an Egyptian study carried out by Abdelaziz et.al., (2015) that stated that positive family history of breast cancer including close relative, increases awareness regarding breast cancer and familial aggregation can be attributed in part due to the shared physical, environmental and lifestyle factors.

\section{CONCLUSION}

Our study findings have shown that the level of awareness and knowledge about breast cancer and breast self-examination was generally moderate. Therefore, it is essential to increase the conduct for public interventions that increase awareness and encourage women to practice BSE on a regular basis as a national trend. At large, these educational workshops should also emphasize on the exact techniques of BSE so that women are able to apply their knowledge effectively and 
perform it on a monthly basis. Correspondingly, all universities should also organize similar sessions so that students can have increased awareness regarding BSE at an earlier age. Also, mass media and social media should be integrated into the planning for raising awareness and increasing women's level of knowledge of breast cancer and breast self-examination on a public level.

\section{Conflict of Interests}

The authors declare that they have no conflict of interest.

\section{ACKNOWLEDGEMENT}

The authors are thankful to the institutional authority for completion of the work.

\section{REFERENCES}

Abdelaziz, S.H., Salem, D., Zaki, H. \& Atteya, S. (2015). Nurse's Role in Early Detection of Breast Cancer through Mammography and Genetic Screening and Its Impact on Patient's Outcome. International Journal of Medical, Health, Biomedical, Bioengineering and Pharmaceutical Engineering, 9(2), pp 155-162.

Adetule, Y.C. (2016). Breast Self-Examination (BSE): A strategy for early detection of breast cancer in Nigeria. Annals of Oncology, 27(suppl_9).

Ahmed, A., Zahid, I., Ladiwala, Z.F.R., Sheikh, R. \& Memon, A.S. (2018). Breast self-examination awareness and practices in young women in developing countries: A survey of female students in Karachi, Pakistan. Journal of Education and Health Promotion, 7.

Ali, A.N., Yuan, F.J., Ying, C.H. \& Ahmed, N.Z. (2019). Awareness, Knowledge and Attitude towards Breast Selfexamination: ACross-sectional Study among Female Pharmacy Students in Malaysia. International Research Journal of Oncology, pp 1-10.

American Cancer Society (2017). History of ACS recommendations for the early detection of cancer in people without symptoms.

Azemfac, K., Christie, S., Carvalho, M.M., Nana, T., Fonje, A.N., Halle-Ekane, G., Dicker, R., Chichom-Mefire, A. \& Juillard, C., (2019). A community-based assessment of knowledge and practice of breast self-examination and prevalence of breast disease in Southwest Cameroon. Journal of Cancer Epidemiology.

Birhane, K., Alemayehu, M., Anawte, B., Gebremariyam, G., Daniel, R., Addis, S., Worke, T., Mohammed, A. \& Negash, W. (2017). Practices of breast self-examination and associated factors among female debre berhan university students. International Journal of Breast Cancer.

Bray, F., Ferlay, J., Soerjomataram, I., Siegel, R.L., Torre, L.A. \& Jemal, A. (2018). Global cancer statistics 2018: GLOBOCAN estimates of incidence and mortality worldwide for 36 cancers in 185 countries. CA: A Cancer Journal for Clinicians, 68(6), pp 394-424.

Dadzi, R. \& Adam, A. (2019). Assessment of knowledge and practice of breast self-examination among reproductive age women in Akatsi South district of Volta region of Ghana. PloS one, 14(12).

Erdem, Ö. \& Toktaş, İ. (2016). Knowledge, attitudes, and behaviors about breast self-examination and mammography among female primary healthcare workers in Diyarbakır, Turkey. BioMed Research International.

Gupta, R., Gupta, S., Mehrotra, R. \& Sodhani, P. (2020). Risk factors of breast cancer and breast self-examination in early detection: systematic review of awareness among Indian women in community and health care professionals. Journal of Public Health, 42(1), pp 118-131.

Gwarzo, U.M.D., Sabitu, K. \& Idris, S.H. (2009). Knowledge and practice of breast self-examination among female undergraduate students. Annals of African medicine, 8(1).

Ibnawadh, S.K., Alawad, M.A., Alharbi, S.S., Alduawihi, N.A., Alkowiter, F.S., Alsalhy, A.E., Alzahrani, A.A. \& Alenizy, L.A. (2017). Knowledge, attitude and practice of breast self-examination among females in medical and non-medical colleges in Qassim University. Journal of Health Specialties, 5(4), pp 219. 
Kifle, M.M., Kidane, E.A., Gebregzabher, N.K., Teweldeberhan, A.M., Sielu, F.N., Kidane, K.H., Weldemenkerios, S.H. \& Tesfay, M.G. (2016). Knowledge and practice of breast self-examination among female college students in Eritrea. AJPHR, 4(4), pp 104-8.

LoBiondo-Wood, G. \& Haber, J. (2017). Methods and Critical Appraisal for Evidence-Based Practice. Elsevier Health Sciences.

Mekonnen, M. \& Asefa, T. (2019). Knowledge, attitude and practice of breast self examination among female undergraduate nursing students at University of Gondar College of Medicine and Health Sciences. Hospice \& Palliative Medicine International Journal, 3(5), pp 167-173.

Mostafa, E.N.A. (2016). Knowledge about breast cancer and it's early detection measures among women with familial risk at Cairo university. Thesis submitted to Cairo University, Egypt.

Nde, F.P., Assob, J.C.N., Kwenti, T.E., Njunda, A.L. \& Tainenbe, T.R.G. (2015). Knowledge, attitude and practice of breast self-examination among female undergraduate students in the University of Buea. BMC Research Notes, 8(1), pp.43.

Oeffinger, K.C., Fontham, E.T., Etzioni, R., Herzig, A., Michaelson, J.S., Shih, Y.C.T., Walter, L.C., Church, T.R., Flowers, C.R., LaMonte, S.J. \& Wolf, A.M. (2015). Breast cancer screening for women at average risk: 2015 guideline update from the American Cancer Society. Jama, 314(15), pp 1599-1614.

Reymen, I.M.M.J., Hammer, D.K., Kroes, P.A., van Aken, J.E., Dorst, C.H., Bax, M.F.T. \& Basten, T. (2006). A domainindependent descriptive design model and its application to structured reflection on design processes. Research in Engineering Design, 16(4), pp.147-173.

Sama, C.B., Dzekem, B., Kehbila, J., Ekabe, C.J., Vofo, B., Abua, N.L., Dingana, T.N., \& Angwafo III, F. (2017). Awareness of breast cancer and breast self-examination among female undergraduate students in a higher teachers training college in Cameroon. Pan African Medical Journal, 28(1), pp.164.

Sayed, S., Ngugi, A., Ochieng, P., Mwenda, A.S. \& Salam, R.A. (2017). Training health workers in clinical breast examination for early detection of breast cancer in low-and middle-income countries. The Cochrane Database of Systematic Reviews, (1).

Taleghani, F., Kianpour, M. \& Tabatabaiyan, M. (2019). Barriers to breast self-examination among Iranian women. Iranian Journal of Nursing and Midwifery Research, 24(2), pp 108. 